\title{
Almost as helpful as good theory: some conceptual possibilities for the online classroom
}

\author{
Mike Davis* and Kate Denning** \\ *Learning Technology Research Institute, University of North London \\ **Research and Graduate School of Education, University of Manchester \\ email:mike.davis@unl.ac.uk
}

Interest and activity in the use of C\&IT in higher education is growing, and while there is effort to understand the complexity of the transition to virtual space, aspects of development, particularly clarity about the nature of the learning community, may only be lightly theorized. Based on an ongoing action research study involving postgraduate students studying in the UK and USA, this paper will identify some theoretical roots and derive from these six conceptual areas that seem to the authors to have relevance and significance for behaviour online. An exploration of these forms the basis for a twodimensional model which can account for what happens when groups come together to learn in cyberspace. In depicting this model, there is acknowledgement of the existence of third and fourth dimensions at work. However, the explanatory power of taking these extra dimensions into account is beyond the scope of the analysis thus far.

\section{Introduction}

Current interest in the use of Communications and Information Technology (C\&IT) in higher education and other settings is at a high level (for example, Framework V: Towards a User-Friendly Information Society; the ESRC Programme PACCIT) and while universities - in response to the Dearing Report - begin to exercise effort in restructuring course delivery methods to take advantage of the technology, there is a danger that the issue of the changes in the social dynamics that are a direct consequence of the transition from actual space to virtual space will be overlooked. Some work has been undertaken in this area (notably Rheingold, 1991; Cook, 1995; McConnell, Hardy and Hodgson, 1996) but there is need for additional research if we are to identify a clearer sense of how effective online learning might manifest itself. We agree with Jones (1998), however, that the technology presents considerable challenges in establishing and maintaining communities: 
The learning process may bring people together insofar as such learning is often collaborative, but it is equally as often frustrating and off-putting. (Jones, 1998: 8)

This paper will explore an approach to postgraduate education which depends on online collaborative construction of knowledge, drawing on students' past experience and new understanding gained on the course. There are other models of practice employing computer-mediated communication (CMC) in postgraduate teaching, but it has been decided to limit the scope of this paper to action science groups (Argyris, Putnam and Smith, 1986) because the nature of the work undertaken by these small groups is intense and personal, providing fertile ground for the creation of the learning community which is the focus of the research. Action Science has been described as the science of interpersonal action' (Argyris, 1993) and is an approach to personal and organizational development. Action science employs a number of methods by which participants examine their work-based defensive routines and look to change their underlying theories-in-use to produce more positive and effective ones. Participants of all six cohorts under consideration here wrote case studies which were then interrogated online by their small group and the two facilitators. A case study in this context is a written record of a remembered conversation about which the case writer feels dissatisfied for some reason. It was expected that learning will occur at two levels. Firstly, each case writer has the opportunity to gain insight into his or her own defensive routines as played out in the original dialogue. Secondly, all group members learn the specific questioning skills required of an action scientist, enhance their ability to spot underlying inconsistencies in a conversation and gain practice in rewriting statements in a new format which is more likely to lead to mutual learning and win-win outcomes.

It is felt that each group within the six cohorts that represents our data set has demonstrated some vivid characteristics. We consider that this rich environment is a source of real insights into the challenges offered by CMC in creating learning communities and this has enabled us to develop a model that goes some way to describing the characteristics of these communities:

There have been almost fifty years of research and theorizing about the way in which groups of various sizes function in a variety of face-to-face settings, including some in higher education classrooms and lecture theatres. Research into CMC has a much shorter history. An examination of the literature persuades us that it is easy to make incorrect assumptions about the characteristics of the online classroom. CMC is often seen simply as another process which can be incorporated into existing thinking and practice, rather than one requiring a shift in conceptualization: about teaching and learning; about groups; and about the effect of technology on their structure and function. As Fernback noted,

We know already that many of the assumptions we hold about the negotiation and formation of social relationships, and particularly about community, do not seem to apply in the complex realm of CMC. (Fernback, 1999: 205)

Not surprisingly, the rhetoric and some of the practice of teaching and learning see CMC as a potential pedagogy for higher education as the capacity of the medium to deliver course materials and to generate interactivity between lecturers and students and among the student body becomes apparent. While the move towards the virtual campus cannot be ignored, there is the need to identify some of its characteristics and the theories underlying 
the practice. The purpose of this paper, therefore, is to explore some of the theory that contributes towards an effective understanding of what takes place when groups of students meet and learn online. In common with standard practice, students' names have been changed. Their contributions to discussion, however, are uncorrected.

\section{Some theoretical possibilities}

While not believing that activity in cyberspace has direct analogies with face-to-face experiences, our thinking is shaped by attention to two main theoretical sources: group dynamics - both from a sociological (Miller, 1993) and a psychoanalytical perspective (Bion, 1961) - and situated learning, particularly its focus on notions of communities of practice, socially constructed knowledge and authentic activity (McLellan, 1996). In the limited space we have available for this paper, we will go no further than claiming a relationship between the components of situated learning identified by McLellan, onto which we have mapped online experience of working with action science.

\begin{tabular}{|c|c|}
\hline Key component & Online experience of action science \\
\hline Stories & The case studies \\
\hline Reflection & Reflecting on and in action through case study interrogation and rewrites \\
\hline Cognitive apprenticeship & Working with 'expert' facilitators \\
\hline Collaboration & $\begin{array}{l}\text { Working collaboratively to reveal defensive routines and to seek win-win } \\
\text { alternatives }\end{array}$ \\
\hline Coaching & Deliberate teaching and modelling of good action science interrogation \\
\hline Multiple practice & $\begin{array}{l}\text { Successive cases during which time participants become more skilled and } \\
\text { confident }\end{array}$ \\
\hline Articulation of learning skills & $\begin{array}{l}\text { The construction of a metadialogue to inform a group's practice and } \\
\text { achievement }\end{array}$ \\
\hline Technology & Making appropriate use of the available technology. \\
\hline
\end{tabular}

Table 1: Relationship between key components of situated learning and online experiences of action science

Our thinking, dominated at the time by consideration of group dynamics, led us to reflect on six conceptual areas which seem to be powerful ingredients in the online classroom:

- social organization

- orientation towards learning

- orientation towards task and/or tutor

- group work modality

- emotional climate

- group response to challenge. 


\section{Social organization}

While communication online can be task-based there is an expectation that other, non-task but socially essential communication will contribute to the growth and sustenance of the community. Sociolinguists call this phatic communication (Stubbs, 1983), and it is seen as essential to maintain effective social interaction. It has been argued (Feenberg, 1989) that $\mathrm{CMC}$ is poor at fulfilling these phatic functions. He writes: 'All such phatic signs are bypassed in computer conferencing. Even standard codes for opening and closing conversations are discarded' (Feenberg, 1989: 22).

This is particularly problematic in online communication because there is only the single, textual cue available for inspection in contrast with the multiple cues that exist in face-toface communication. Evidence from previous studies in CMC (Davis, 1997; Davis and Holt, 1998) suggests that this form of interchange may not arise spontaneously and its absence can contribute towards social isolation and withdrawal. There are models that suggest that remediation of this is possible using a number of straightforward strategies, such as sending private email messages, directing comments at individuals and modelling responsiveness (Harasim, Hiltz, Teles and Turoff, 1995; Midoro, 1999). The research is key both to identify and to refine appropriate facilitation strategies to maximize effective learner participation and interdependence. Positive outcomes of well-timed and wellcrafted tutor interventions include independence and community. However, whilst independence can be a rewarding outcome of a learning experience, it can also work against effective community membership.

\section{Orientation towards learning}

Orientation towards learning has two related continua:

$$
\begin{aligned}
& \text { individual } \longrightarrow \text { cooperative } \longrightarrow \text { collaborative } \\
& \text { dependent } \longrightarrow \text { independent } \longrightarrow \text { interdependent }
\end{aligned}
$$

Collaborative, interdependent learning, which is that discovered in a learning community, can be understood 'as a distributed, ongoing social process, where evidence that learning is occurring or has occurred must be found in understanding the ways in which people collaboratively do learning and do recognize learning as having occurred' (Jordan, 1996: 42). Collaborative learning occurs when participants mutually engage 'in a coordinated effort to solve [a] problem together' (Roschelle and Behrend, 1995: 70). Whipple describes the benefits of collaborative learning:

collaboration results in a level of knowledge within the group that is greater than the sum of the knowledge of the individual participants. Collaborative activities lead to cmergent knowledge, which is the result of interaction between (not summation of) the understandings of those who contribute to its formation. (Whipple, 1987:5)

In contrast, Hiltz, describing the software they use, writes: 'This assignment was carried out using the 'activity branch' software. In a response branch, each student must answer the question before being able to read the answer of others' (Hiltz, 1994: 59).

This kind of structure may work counter to attempts at building a learning community. Whilst the focus is on ensuring that the individual learner thinks, then an interactive 
building of ideas is absent and it becomes unlikely that collaborative learning can take place or a learning community emerge.

\section{Orientation towards task/tutor}

A classic depiction (Bennis and Shepard, 1956) of group life is that it can be divided into two main phases: dependence-power relations and interdependence-personal relations, and it is this that determines the orientation towards the task and the tutor. In dependence-power relations, students engage in flight from the task through avoidance and reliance on social engagement to occupy time. Counterdependency - a metaphorical fight with authority can also emerge. The shift into interdependence-personal relations leads to conditions where there is considerably less dependence on external authority - either in the shape of the task or the tutor - and the development of a shared sense of responsibility for group performance. In online communities, this can create conditions in which members feel addicted to the process. In sharp contrast to this condition is the total separation of self from others: the condition of anomie 'when members of a superficially well-organised society feel disconnected and isolated' (Reber, 1995: 39).

\section{Group work modality}

Group life can also be characterized from a more psychological perspective, originally modelled by Wilfred Bion (Bion, 1961). Fundamental to Bion's thinking about groups is that membership of them is part of the human condition. As he wrote: 'no individual, however isolated in time and space, can be regarded as outside a group, or lacking in active manifestations of group psychology' (Bion, 1961: 132).

Bion proposed that groups work at two levels. Work groups function effectively, engage with the task and with one another and attend to the needs of the group. According to Bion, however, whilst a group is operating in 'work' mode it is also capable of being subverted at any one time by one of the three basic assumptions - dependence, flight/fight or pairing.

A group moves into basic assumption dependency whenever it is reliant on a leader and believes that the leader will control, make decisions and rein in any passions that are too threatening to the safety of the group. A group in conflict or under pressure will often move into denial manifest as flight (running away from a difficult issue to talk about 'safer' topics) or fight (usually a verbal struggle). A group is considered to be in basic assumption pairing when two members of the group are heavily involved in a discussion and the remainder of the group is silent but attentive. It is likely that a series of pairs will emerge, each dominating the discussion for a while. Basic assumption groups are thought to be mutually exclusive: for example, a group in basic assumption pairing cannot demonstrate flight/fight or dependency-type behaviour. It is possible for a group to move readily from one basic assumption to another.

\section{Emotional climate}

All of the above conditions represent a challenge to the group and this challenge contributes towards an emotional reaction, either shared or individual. Among these, we have identified indifference (real or otherwise), frustration, off-task fascination, and 
anxiety. The first three are counterproductive in respect of the success of the group and/or its task completion. The latter can be productive or its opposite: too high anxiety invariably leads to ineffectiveness or, in the worst case, withdrawal; too low is insufficient to drive the motor of learning.

\section{Group response to challenge}

Groups respond to challenge at different times in different ways. Our experience has led us to identify four responses: groups that become hostile to the task reveal passive resistance or aggression, often by showing little interest in the activity; others deny that there is a problem when attempts are made to establish dialogue about the events unfolding. Others become fascinated with membership of the group and are seduced by the social aspects of their communication. Successful groups, however, engage in risk-taking: challenging other members, indeed challenging themselves, to push the margins of what is possible.

\section{Discussion}

In an attempt to gain some insight into how these conceptual areas might inter-relate, we chose a $2 \times 2$ matrix (see Figure 1) to characterize four archetypal groups.

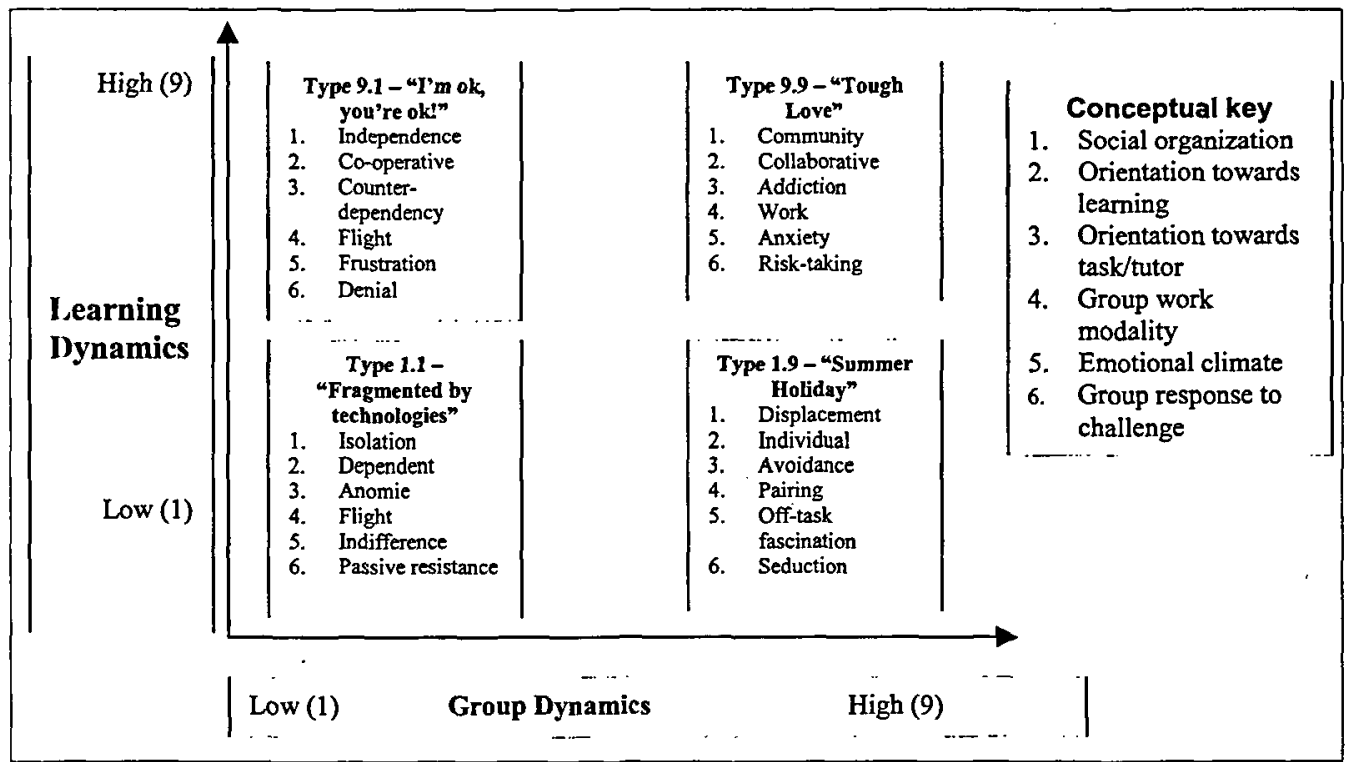

Figure 1: Group functioning in cyberspace (Davis and Denning, 2000)

\section{Fragmented by technologies (I.I)}

A group which is low on both learning and group dynamics may have very little activity and will not be concerned about the group processes nor will it be effective in its learning objectives. Members will be isolated from one another and their approach to learning, where it exists, is individual. Socially, group members are isolated and their basic assumption is flight - from the task and any discussion about the task. This leads to public 
indifference (despite email messages that indicate private frustration and anger) and a group strategy of passive resistance or aggression. Whilst successful groups showed themselves willing to build upon each other's ideas and create new levels of understanding, other groups never gained any momentum:

Hilary: I am not really enjoying our group interaction. It is very slow and uninvolved and the communication levels are very low. I am finding it hard to find questions to ask. I don't know why.

A willingness to avoid the task and discussion about the task is well summed up by one case-writer who commented on his own case as follows:

Jack: $\mathrm{i}$ [sic] have reviewed your input, and appreciated your interest. the questions that were asked will help me focus on the situation.

Since this particular casewriter only made two interventions into his own case (the average for one of the cohorts was twenty-six) this represents 50 per cent of his output and clearly the experience has made little positive impact on him and the rest of the group.

\section{Summer Holiday (1.9)}

If a group is high on group dynamics but low on learning dynamics then group members may be having a lot of fun whilst achieving little learning. Here, members are displaced from normal life and they demonstrate self-interest and individuality. Work is avoided and the complex notion of basic assumption pairing is acted out. In this, the group waits for a magical event to emerge from possible pairing of other participants. Accordingly, they can be high on social interaction - invariably manifested through social 'conversation' at the expense of work. Indeed, the social is the dominant theme in this type of group and this, of course, can be very satisfying for the members and is very seductive. The following example demonstrates a group being hampered by notions of the need to be inclusive whilst at the same time struggling with the process of making decisions online.

Laura: since nobody is taking the initiative but everybody seems to share the view (at least this is what I make out of it) I would like to see how many of you could make it for an on line session, real time sometime this satarday [sic] or Sunday afternoon. This is the time that I can make it if you think that some other time is more convinient [sic] please suggest it.

This comment came in week four of seven weeks when the group had already been discussing meeting synchronously (at the same time as each other) since the first week. It seems likely that the social element was so important for this group that the thought of meeting up at a time that didn't suit all of them was unthinkable. The group continued to resist moves by various members to experiment with synchronous communication until, in week six, the following intervention from one of the tutors coincided with the most innovative member being more proactive about her desires.

Jack: Would $7 \mathrm{pm}$ on tonight and on Wednesday night suit everyone?

Kate (Facilitator): I think trying to get everyone may be a mistake. All you need is the casewriter and one or two others. More is obviously great, but not essential. I sense waiting for everyone to agree could mean that yet again you fail to meet. 
Jack: that's true, Kate ... I had forgotten that that time would not be convenient for all ... so who will meet me on line ... I'll be here at $7.00 \mathrm{pm}$.

And she was. Those that met up with her clearly enjoyed 'being' together, but continued to use the time in a largely social way. Although the group had managed to overcome one of its difficulties (making decisions) it was unable to work against the by now well established norm of social activity dominating the work space.

\section{I'm ok, you're ok (9.1)}

If a group is high on learning dynamics but low on group dynamics then members will show little concern for each other personally and will tend to work independently rather than interdependently. One group whose group strategy we have characterized as denial had the following conversation:

Megan: I am aware that there are a number of things I have been thinking but not saying and $I$ wonder if this is true for others also.

Rod: M, I too feel that perhaps we aren't as active as we could be. But I am OK with it.

Here Rod refused to take up the gauntlet, preferring to work in her own way which Megan later described as 'bullying'.

Such groups are capable of acting co-operatively rather than collaboratively. In the latter, understanding and insight grow from the social construction of knowledge. In the former, it is more competitive and individual understanding and insight is the desired outcome, possibly at the expense of others' learning. Inevitably, groups who find themselves in this situation demonstrate counter-dependent behaviour with frequent (although invariably unsuccessful) appeals to authority to deal with the problematic group dynamics. Equally inevitably, tutors are held responsible for their failure to make the groups work more effectively and members deny their collective and individual responsibilities for the difficulties the group is experiencing.

Below is an extract from a group who struggled and looked to the tutors to make the interaction more productive.

Sue: MikeD, Kate, correct me if I'm wrong but I thought that in order for a case to be completed, it was necessary to provide the 'interrogated' with a TIU. This didn't happen in my case.

Kelly: yes, S. I am also interested in getting an answer to this question, you will remember that I raised a similar concern to Kate and MikeD last time when my case was discussed, but I did not get any satisfactory response. As for MikeD, he did not even bother to comment on the issue. With Kate it was better because, even if she did not answer my question, she at least asked me questions in relation to the issue.

Here we have two group members whose primary concern is that they gain from the experience without necessarily giving to the rest of the group. Both are requesting a theoryin-use from members of the group, neither were very forthcoming in giving them to others. This demonstrates a group attempting to learn individually in an environment set up for collaborative learning. It is not possible to do action science alone. If it were possible they would have done it! 


\section{Tough Love (9.9)}

Groups who manage both group dynamics and learning dynamics get as close as is possible to becoming a learning community. They behave in a collaborative manner, in particular in checking out assumptions and perceptions with other group members.

Kate: I'm going to be really mean now Rod and assume that 'Ooh that's harsh' means I hit the nail on the head there. Is my assumption correct?

The work of the group takes on an incredible pace and volume: students report logging in at all times of the day and night and many independently have talked of how addictive the process is.

Jackie: I agree about this becoming somewhat addictive. I find myself wanting to checking $[s i c]$ several times daily.

The consequence of volume and intensity is that considerable insight is developed into the interpersonal processes under exploration through the action science cases.

Jackie: What has been very revealing for me in these 2 days has been the emotion evoked at my keyboard. I have had more than a couple of moments where a light has come on, a bell clanged, or several ahas. I've been all teared up in several of my responses tonight. I've experienced many things sitting and reflecting [...] What I find so amazing and possibly the real truth is how all of you see through my coverup.

Action science, as an organizational intervention, is very powerful but it can raise high levels of anxiety given that the design is to explore participants' interpersonal incompetence. Frequently people act out the characteristics of their case during interrogation, and that makes necessary risk-taking. One group had a difficult first week with only three of its members contributing actively to the discussion. After several days Pete (following email correspondence with one of the facilitators) posted this message:

Pete: I have been following but rather in what to me is an awkward position. I don't know why I suddenly chose to be an observer in this discussion ...

He received a number of responses from the active members letting him know how hard they had been working to keep the group moving with such low 'attendance'. One of the replies indicated a broader awareness both of the effect his silence had on the group and of the reciprocal nature of the work.

Jackie: I realise that it isn't always easy [sic] to get to your computer but if we can at least check in at the beginning of the cases and if we are not going to be able to make comments for whatever reasons at least inform each other of that so that we are aware of what is going on. I think this would help us all to work more effectively as a group. We are all presenting cases here and I assume that we would all like all members of the group to contribute to this otherwise how can we be a group??

This marks a clear challenge to the 'observer' stance Pete had been taking - if you want us to work for you, then you have to work for us. Pete took up the challenge, apologized to the group and began making effective interventions. This early friction was one of the key moments for this group who went on to produce some high-quality work. 
As has been mentioned earlier one of the elements of the group whose orientation towards learning is collaborative is that the knowledge is constructed together by the sharing of thoughts, feelings and knowledge. This building of ideas results in higher-order insights than might be gained individually. One participant commented on how the group seemed to be building individual lines of enquiry rather than working together, which, whilst it was true, was a comment which itself was part of the following scaffold:

Kelly: I find Karen [facilitator] has made an intervention that has set me thinking ...

Jackie: Just to tag on to K's response . . .

Megan: Good job K you've hit a big problem on the head ... maybe one solution is ...

Our model, as it stands, assigns to each of the six conceptual areas four potential states to correspond to the creation of four ideal group types. This, however, is a misrepresentation of the complexity of the model we have created, as much as anything else for neatness of exposition. What we are aware of is a third dimension, not accommodated by the 2 by 2 matrix, which can indicate possible alternative alignments of the various characteristics of behaviour and their interrelationship. This we have designated depth (the fact that a conceptual area can be manifest in a number of ways) and see it as the third dimension of the model which as yet remains in its infancy. The danger, however, here is that we fall into the trap identified by Aarseth:

the race is on to conquer and colonise these [learning technologies] for our existing paradigms and theories, often in the form of 'the theoretical perspective of $<$ fill in your favourite theory/theoretician here $>$ is clearly really a prediction/description of $<$ fill in your favourite digital medium here $>$.' This method is being used with permutational efficiency throughout the fields of digital technology and critical theory, two unlikely tango partners indeed. But the combinatorial process shows no sign of exhaustion yet. (Aarseth, 1999: 31)

At least we are aware of this risk, and we will remind ourselves of it from time to time.

\section{Conclusion}

So, what, if anything, can we conclude? The model depicted in Figure 1 was the product of inspiration and intuition based on our iterative analysis of data collected over a three-year period and it feels as if it has some explanatory power. We plan to re-examine our data in an attempt to confirm the accuracy of the conclusions we have drawn. We then want to examine other data from other online courses that are similar in nature to see if the model, as it currently stands, is robust. Then we might be able to tackle the third dimension, depth, and the, as yet unmentioned, fourth dimension of time.

\section{References}

Aarseth, E. (1999), 'Aporia and epiphany in doom and the speaking clock: the temporality of ergodic art', in M. Ryan (ed.), Cyberspace Textuality: Computer Technology and Literary Theory, Bloomington: Indiana University Press.

Argyris, C. (1993), Knowledge for Action, San Francisco: Jossey-Bass. 
Argyris, C., Putnam, R. and Smith, D. (1986), Action Science, San Francisco: Jossey-Bass.

Bennis, W. and Shepard, H. (1956), 'A theory of group development', Human Relations, IX (4), 415-38.

Bion, W. (1961), Experiences in Groups and Other Papers, London: Tavistock.

Cook, D. (1995), 'Community and computer-generated distance learning environments', New Directions for Adult and Continuing Education, 67, 33-9.

Davis, M. (1997), 'Fragmented by technologies: a community in cyberspace', Interpersonal Communication and Technology Journal, 5 (1/2), 7-18.

Davis, M. and Holt, M. (1998), 'Havingproblems@cm.com: new ways to miss the point', Innovative Higher Education, 22, 4, 311-27.

Davis, M. and Denning, K. (2000), 'Online learning: frontiers in the creation of learning communities', Proceedings of the Networked Learning 2000 Conference, University of Lancaster.

de Board, R. (1978), The Psychoanalysis of Organisations, London: Tavistock.

Feenberg, A. (1989), 'The written world: on the theory and practice of computer conferencing', in R. Mason and A. Kaye (eds.), Mindweave: Communication, Computers and Distance Education, Leicester: Pergamon.

Fernback, J. (1999), 'There is a there there: notes toward a definition of cybercommunity', in S. Jones (ed.), Doing Internet Research: Critical Issues and Methods for Examining the Net, London: Sage, 203-20.

Grinberg, L., Sor, D. and Tabak de Bianchedi, E. (1975), Introduction to the Work of Bion (trans. A. Hahn), London: Maresfield Library.

Harasim, L., Hiltz, S., Teles, L. and Turoff, M. (1995), Learning Networks: A Field Guide to Teaching and Learning Online, Cambridge, MA: MIT Press.

Hiltz, S. (1994), The Virtual Classroom: Learning without Limits via Computer Networks, Norwood, NJ: Ablex Publishing Corporation.

Jones, S. (ed.) (1998), Cybersociety 2.0: Revisiting Computer-mediated Communication and Community, Thousand Oaks: Sage.

Jordan, B. (1996), 'Ethnographic workplace studies and CSCW', in D. Shapiro, M. Tauber and R. Traunmuller (eds.), The Design of Computer Supported Cooperative Work and Groupware Systems, Amsterdam: Elsevier.

McConnell, D., Hardy, V. and Hodgson, V. (1996), Groupwork in Educational Computer Conferences. Final Report to ESRC, DACE, University of Sheffield, http://www.shef.ac.uk/ unilprojects/csnll.

McLellan, H. (ed.) (1996), Situated LEARNING Perspectives, Englewood Cliffs, NJ: Educational Technology Publications.

Miller, N. (1993), 'How the T-group changed my life: a sociological perspective on experiential group work', in D. Boud, R. Cohen and D. Walker (eds.), Using Experience for Learning, Buckingham: SRHE/Open University Press. 
Midoro, V. (1999), 'Modelling online education', in Communications and Networking in Education: Learning in a Networked Society, Proceedings of IFIP Working Groups 3.1, 3.5 and 3.6 Open Conference, Aulanko-Hameenlinna, Finland, 13-18 June 1999, 239-46.

Reber, A. (1995), The Penguin Dictionary of Psychology, 2nd edition, Harmondsworth: Penguin.

Rheingold, H. (1991), Virtual Reality, London: Mandarin.

Roschelle, J., and Behrend, S. (1995), 'The construction of shared knowledge in collaborative problem solving', in C. O'Malley (ed.), Computer-supported Collaborative Learning, Berlin: Springer-Verlag.

Stubbs, M. (1983), Discourse Analysis: The Sociolinguistic Analysis of Natural Language, Oxford: Basil Blackwell.

Whipple, W. (1987), 'Collaborative learning: recognizing it when we see it', Bulletin of the American Association for Higher Education, 40, 2, 3-7. 